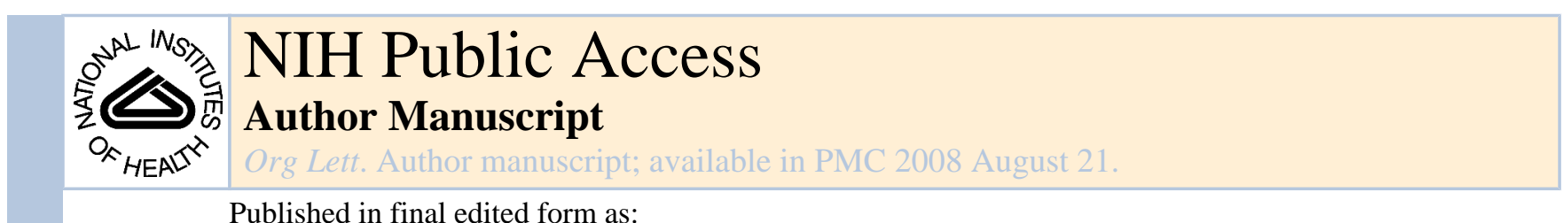

Published in final edited form as:

Org Lett. 2006 August 31; 8(18): 4067-4070.

\title{
Phaeosphaeride A, an inhibitor of STAT3-dependent signaling isolated from an endophytic fungus
}

\author{
Katherine N. Maloney ${ }^{\dagger}$, Wenshan $\mathrm{Hao}^{\ddagger}$, Jun $\mathrm{Xu}^{\ddagger}$, Jay Gibbons ${ }^{\ddagger}$, John Hucul§, Deborah \\ Roll§, Sean F. Brady $\uparrow$, Frank C. Schroeder ${ }^{\dagger}$, and Jon Clardy ${ }^{\dagger}$ \\ Department of Biological Chemistry and Molecular Pharmacology, Harvard Medical School, Boston, \\ Massachusetts 02115
}

\begin{abstract}

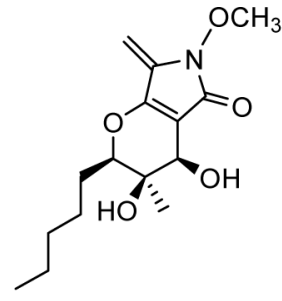

phaeosphaeride A

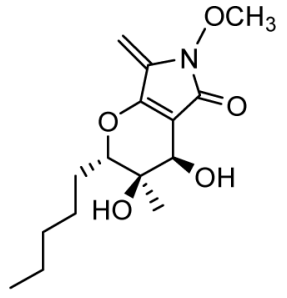

phaeosphaeride $\mathrm{B}$

Phaeosphaeride A, a nitrogen-containing bicyclic compound produced by an endophytic fungus, inhibits signaling by the transcription factor STAT3.
\end{abstract}

\begin{abstract}
Signal transducer and activator of transcription (STAT) 3 plays a vital role in regulating cell growth and survival. In response to growth factor and cytokine stimulation, STAT3 is phosphorylated, dimerizes, and translocates into the nucleus to up-regulate transcription of a wide spectrum of genes. In many cancers - including breast, ${ }^{1}$ prostate, ${ }^{2}$ ovarian, ${ }^{3}$ and skin ${ }^{4}$ - constitutively activated STAT3 inappropriately upregulates genes that promote angiogenesis ${ }^{5}$ and prevent apoptosis. ${ }^{6}$ A constitutively active mutant STAT3 is sufficient to cause cell transformation and tumor formation. ${ }^{7}$
\end{abstract}

The short STAT3 pathway offers few opportunities for small molecule therapeutic intervention. The natural products cucurbitacin I (1) and resveratrol (2) both inhibit STAT3 activity by targeting tyrosine kinase activators, ${ }^{8}$ and the semisynthetic flavone flavopiridol (3) interferes with STAT3 binding to DNA. ${ }^{9}$ Flavopiridol is in phase I clinical cancer trials, but in addition to disrupting STAT3-DNA binding, flavopiridol also inhibits several growth promoting kinases. ${ }^{10}$ In an effort to identify other small molecule inhibitors of STAT3, a 10,000 -member library consisting primarily of natural product extracts was screened for the ability to disrupt STAT3-DNA binding. Active molecules were detected by adding test samples to cell lysate containing activated STAT3 and incubating in oligonucleotide-coated wells displaying the STAT3-binding sequence. Extracts that inhibited STAT3-DNA binding were detected by ELISA using a STAT3-specific primary antibody and horseradish-peroxidase-

\footnotetext{
jon_clardy@hms.harvard.edu.

tDepartment of Biological Chemistry and Molecular Pharmacology, Harvard Medical School.

\$Department of Discovery Oncology, Wyeth Research, Pearl River, NY 10965, USA.

$\S$ Department of Chemical and Screening Sciences, Wyeth Research, Pearl River, NY 10965, USA.
}

Supporting Information Available Large subunit rDNA sequence of FA39, ELISA and cell growth assay data for 4, and NMR spectra of $\mathbf{4}$ and $\mathbf{5}$ in DMSO, and of $\mathbf{6}$ and $\mathbf{7}$ in methanol. 
linked secondary antibody. ${ }^{11}$ This paper reports the isolation of phaeosphaeride A (4), an inhibitor of STAT3 signaling, and its inactive diastereomer phaeosphaeride B (5).

Endophytic fungi were isolated from plant samples collected in the Archbold Biological Station, a five-thousand-acre preserve in Lake Placid, Florida, which is home to an exceptionally high concentration of endemic and endangered plant species representing the distinct evolutionary history of the Florida highlands. ${ }^{12}$ In order to identify STAT3 inhibitors, organic extracts of fungal cultures were added to cell lysate.

Endophyte FA39 showed uniquely potent activity against STAT3. FA39 was identified by rDNA sequence ${ }^{13}$ as having $97 \%$ identity to the ascomycete Phaeosphaeria avenaria, the causative agent for a blotch disease of cereals. In an effort to maximize production of STAT3 inhibitory activity, FA39 was grown under a variety of conditions. Interestingly, only the extracts from cultures grown on a breakfast cereal showed activity against STAT3. ${ }^{14}$

In order to purify the STAT3 inhibitory compounds, fungal material was first extracted exhaustively with methanol, and the extract clarified by centrifugation prior to evaporation in vacuo. Isolation began with solvent partitioning. The extract was redissolved in $90 \%$ aqueous methanol and defatted with hexanes. The methanolic fraction was then adjusted to $60 \%$ aqueous methanol and partitioned with dichloromethane. The dichloromethane fraction was subjected to chromatography on silica gel (50:1 dichloromethane:methanol eluent), followed by reversed-phase HPLC (65\% aqueous acetonitrile eluent) to give pure phaeosphaeride A (4).

Phaeosphaeride A (4) ${ }^{16}$ was obtained as an optically active $\left([\alpha]^{25}{ }_{\mathrm{D}}-93.6\left(c 2.0, \mathrm{CH}_{2} \mathrm{Cl}_{2}\right)\right)$ yellow glass.

HRESIMS revealed an $[\mathrm{M}+1]^{+}$ion with exact mass 298.1656, corresponding to the molecular formula $\mathrm{C}_{15} \mathrm{H}_{23} \mathrm{NO}_{5}+\mathrm{H}$ (calcd 298.1654), and five degrees of unsaturation. The ${ }^{13} \mathrm{C}$ NMR spectrum of $\mathbf{4}$ contained 15 carbon resonances, consistent with the HRMS data. Comparison of the ${ }^{13} \mathrm{C}$ NMR and DEPT spectra of $\mathbf{4}$ revealed five quaternary carbons, two methine carbons, five methylene carbons, and three methyl carbons. Attached protons for each carbon were established by ${ }^{1} \mathrm{H}-{ }^{13} \mathrm{C}$ HMQC.

Three spin systems were observed in the double quantum-filtered ${ }^{1} \mathrm{H}-{ }^{1} \mathrm{H}$ COSY (dqfCOSY) spectrum of 4 in DMSO- $d_{6}$ (Figure 3a). One spin system extended from the methyl protons at $\delta 0.85(\mathrm{H}-13)$ through four sets of methylene protons $(\delta 1.28, \mathrm{H}-12 ; 1.27, \mathrm{H}-11 ; 1.44, \mathrm{H}-10$; 1.51 and $1.82, \mathrm{H}-9)$ to the methine proton at $\delta 4.07(\mathrm{H}-8)$, corresponding to a straight six-carbon chain. A second spin system consisted of the two protons of a terminal alkene ( $\delta 4.96$ and 4.97 , $J=1.8 \mathrm{~Hz}, \mathrm{H}-14)$. Lastly, a proton at $\delta 3.86(\mathrm{H}-6)$ coupled to a proton signal at $\delta 5.44(\mathrm{OH}-6$, $J=5.3 \mathrm{~Hz}$ ). The latter signal was not observed in the ${ }^{1} \mathrm{H}$ NMR spectrum taken in $\mathrm{CD}_{3} \mathrm{OD}$, indicating an exchangeable proton.

Correlations seen in the ${ }^{1} \mathrm{H}_{-}{ }^{13} \mathrm{C}$ HMBC spectrum of $\mathbf{4}$ established the carbon skeleton shown in Figure 3b. Methyl protons at $\delta 1.18(\mathrm{H}-15)$ and an exchangeable proton at proton at $\delta 4.92$ $(\mathrm{OH}-7)$ both showed strong correlations to methine carbons at $\delta 64.1$ (C-6), and $86.2(\mathrm{C}-8)$, and to the quaternary carbon at $\delta 70.8(\mathrm{C}-7)$, thus establishing the connectivity of carbons $\mathrm{C}-6$ through $\mathrm{C}-8$, and the methyl and hydroxyl groups attached to $\mathrm{C}-7$. The methine proton at $\delta$ $3.86(\mathrm{H}-6)$ showed ${ }^{1} \mathrm{H}^{-13} \mathrm{C}$ HMBC correlations to carbons at $\delta 104.7(\mathrm{C}-5), 155.2(\mathrm{C}-4)$, and 166.5 (C-1), in addition to (redundant) correlations to carbons C-7 and C-8 ( $\delta 70.8$ and 86.2, respectively). No other proton resonances showed correlations to $\mathrm{C}-1$ ( $\delta 166.5)$. The terminal alkene protons ( $\delta 4.96$ and 4.97, H-14) showed strong correlations to the carbon at $\delta 155.2$ (C-4) and to a carbon at $\delta 137.0$ (C-3). C-3 can only be located between C-14 and C-4. An observed correlation from the methine proton $\mathrm{H}-8(\delta 4.07)$ to $\mathrm{C}-4(\delta 155.2)$ can only be 
explained if carbons C-4 through C-8 are arranged in a ring. The chemical shifts of C-4 ( $\delta$ $155.2)$ and $C-8(\delta 86.2)$ indicate they are connected by oxygen.

Of the five degrees of unsaturation allowed by the molecular formula, four are accounted for by the ring (connecting carbons C-4 through C-8), two double bonds (between C-4 and C-5, $\mathrm{C}-3$ and C-14), and a carbonyl group at C-1 ( $\delta 166.5)$. Only a methyl group and one atom each of nitrogen and oxygen remain from the molecular formula. The remaining methyl group is very highly deshielded, with a carbon chemical shift of $\delta 63.7$ and proton shift of $\delta 3.79(\mathrm{H}-16)$, and hence must be attached to oxygen. The structure shown as $\mathbf{4}$ is the only structure consistent with all the NMR data and with the molecular formula determined by HRMS.

The phase-sensitive NOESY spectrum of $\mathbf{4}$ showed a strong correlation between the deshielded methyl protons at $\delta 3.79(\mathrm{H}-16)$ and the terminal alkene proton at $\delta 4.96(\mathrm{H}-14)$, confirming the placement of this methyl group (Figure 3c). The NOE data are most consistent with the relative stereochemistry shown in Figure 3c. An NOE correlation between methine protons H-6 ( $\delta 3.86)$ and H-8 ( $\delta 4.07)$ establish the pseudodiaxial relationship of these hydrogens. Strong positive NOE correlations between both of these hydrogens and methyl protons H-15 $(\delta 1.18)$; as well as between the two $\mathrm{OH}$ protons $(\delta 5.44, \mathrm{OH}-6$; and $\delta 4.92, \mathrm{OH}-7)$ suggest that both hydroxyls and the C- 8 alkyl chain are on the same face.

To confirm the configuration at C-7, $p$-bromobenzoyl derivatives of phaeosphaeride A (4) were prepared. ${ }^{17}$ The major product was determined by NMR to be the mono-p-bromobenzoyl derivative of phaeosphaeride A (6). A second, minor product was demonstrated to be the tri$p$-bromobenzoyl derivative (7) (Figure 4). Attempts to crystallize $\mathbf{6}$ and $\mathbf{7}$ were unsuccessful. However, NOE spectra for each compound in DMSO- $d_{6}$ provided additional evidence for the relative stereochemistry shown. NOE correlations between the methyl H-15 protons $(\delta 1.20$ in 6; 1.21 in 7) and both pseudodiaxial protons $\mathrm{H}-6$ and $\mathrm{H}-8$ ( $\delta 5.78$ and 4.31 in $\mathbf{6}$, respectively; 5.75 and 4.16 in 7) were stronger in $\mathbf{6}$ and $\mathbf{7}$ than in $\mathbf{4}$; presumably the additional steric bulk provided by the bromobenzoyl substitutions enforces a more defined pseudochair conformation in the six-member ring.

Examination of the ${ }^{1} \mathrm{H}$ NMR spectra of the inactive fractions from FA39 revealed a relative of phaeosphaeride A that eluted earlier from the silica column (20:1 dichloromethane:methanol eluent). This compound was also purified by reversed-phase HPLC (70\% aqueous acetonitrile eluent) to give pure phaeosphaeride B (5).

Phaeosphaeride B (5) ${ }^{18}$ was obtained as an optically active $\left([\alpha]^{25}{ }_{\mathrm{D}}-157.2\left(c 2.0, \mathrm{CH}_{2} \mathrm{Cl}_{2}\right)\right)$ orange glass. HRESIMS revealed an $[\mathrm{M}+1]^{+}$ion with exact mass 298.1660 , which is consistent with a molecular formula of $\mathrm{C}_{15} \mathrm{H}_{23} \mathrm{NO}_{5}+\mathrm{H}$ (calcd 298.1654), the same molecular formula as phaeosphaeride $\mathrm{A}(\mathbf{4}) .{ }^{1} \mathrm{H}$ and ${ }^{13} \mathrm{C}$ NMR spectra of 5 were nearly identical to those for 4 . The only significant differences were the carbon chemical shift at C-8 $(\delta 80.3$ in $\mathbf{5}$, compared to 86.2 in 4); and the carbon and proton chemical shifts of the methyl group C-15 ( $\delta 17.9$ and 0.88 in $\mathbf{5}$, respectively; 20.5 and 1.18 in $\mathbf{4}$ ). The NOESY spectrum of 5 lacked the diaxial correlation between the methine protons $\mathrm{H}-6$ and $\mathrm{H}-8$, indicating that $\mathbf{5}$ is a diastereomer of 4, differing in the stereochemical configuration at C-8.

The phaeosphaerides are related to several families of fungal metabolites, most notably the curvupallides, e.g. curvupallide A (8) isolated from Curvularia pallescens, 19 and the lipidlowering spirostaphylotrichins/triticones, e.g. spirostaphylotrichin A/triticone C (9) (Figure 5) isolated independently from Staphylotrichum coccosporum 20 and from Drechslera triticirepentis. ${ }^{21}$ These families of compounds share the unusual $o$-methyl hydroxamic acid functional group of the phaeosphaerides. However, the phaeosphaerides have a previously unreported methyl group at C-15. 
Phaeosphaeride A (4) inhibited STAT3 with an $\mathrm{IC}_{50}$ of $0.61 \mathrm{mM}$ in the primary ELISA-based screen. However, when tested in vivo using STAT3-dependent U266 multiple myeloma cells, phaeosphaeride A (4) was almost 100-fold more potent, inhibiting cell growth with an $\mathrm{IC}_{50}$ of $6.7 \mu \mathrm{M}$, suggesting that $\mathbf{4}$ may have another target in cells. An additional target for $\mathbf{4}$ was also suggested by its low $\mu \mathrm{M}$ activity against the STAT3-independent K562 cell line.

Phaeosphaeride A (4) is selective for STAT3 over other STAT proteins; it has only slight activity against STAT1 from U937 cells, and no activity against STAT5 from Nb2 cells in the ELISA-based assay (Figure 6). Phaeosphaeride A (4) was also active against STAT3 from a second cancer cell line (HepG2). Interestingly, its diastereomer phaeosphaeride B (5) showed no activity against STAT3.

We have identified two fungal metabolites based on a new carbon skeleton, one of which is an inhibitor of STAT3 signaling. The phaeosphaerides join the growing number of pharmaceutically useful natural products from endophytic fungi. ${ }^{22}$

\title{
Supplementary Material
}

Refer to Web version on PubMed Central for supplementary material.

\begin{abstract}
Acknowledgment
This research was supported by a NIH-NCDDG grant (CA67786). K.M. was supported by an NSF Graduate Research Fellowship. HRESIMS was performed by Steve Mullen of the Mass Spectrometry Facility at the University of Illinois at Urbana Champaign. Optical rotation and IR data were obtained with help from Sang Kyun Kim in the laboratory of Eric Jacobsen of the Department of Chemistry and Chemical Biology at Harvard University.
\end{abstract}

\section{References}

1. Garcia R, Yu CL, Hudnall A, Catlett R, Nelson KL, Smithgall T, Fujita DJ, Ethier SP, Jove R. Cell. Growth Differ 1997;8:1267-1276. [PubMed: 9419415]

2. Lou W, Ni Z, Dyer K, Tweardy DJ, Gao AC. Prostate 2000;42:239-242. [PubMed: 10639195]

3. Silver DL, Naora H, Liu J, Cheng W, Montell DJ. Cancer Res 2004;64:3550-3558. [PubMed: 15150111]

4. Pansky A, Hildebrand P, Fasler-Kan E, Baselgia L, Ketterer S, Beglinger C, Heim MH. Int. J. Cancer 2000;85:720-725. [PubMed: 10699955]

5. Niu G, Wright KL, Huang M, Song L, Haura E, Turkson J, Zhang S, Wang T, Sinibaldi D, Coppola D, Heller R, Ellis LM, Karras J, Bromberg J, Pardoll D, Jove R, Yu H. Oncogene 2002;21:2000-2008. [PubMed: 11960372]

6. Shen Y, Devgan G, Darnell JE Jr. Bromberg JF. Proc. Natl. Acad. Sci. U S A 2001;98:1543-1548. [PubMed: 11171987]

7. Bromberg JF, Wrzeszczynska MH, Devgan G, Zhao Y, Pestell RG, Albanese C, Darnell JE Jr. Cell 1999;98:295-303. [PubMed: 10458605]

8. a Jing N, Tweardy DJ. Anticancer Drugs 2005;16:601-607. [PubMed: 15930886] b Kotha A, Sekharam M, Cilenti L, Siddiquee K, Khaled A, Zervos AS, Carter B, Turkson J, Jove R. Mol. Cancer Ther 2006;5:621-629. [PubMed: 16546976]

9. Lee YK, Isham CR, Kaufman SH, Bible KC. Mol. Cancer Ther 2006;5:138-148. [PubMed: 16432172]

10. El-Rayes BF, Gadgeel S, Parchment R, Lorusso P, Philip PA. Invest. New Drugs 2006;24:305-310. [PubMed: 16683073]

11. The assay was performed using the Trans-AM STAT Transcription Factor Assay Kit (Active Motif North America, Carlsbad, CA), according to manufacturer instructions.

12. Dobson AP, Rodriguez JP, Roberts WM, Wilcove DS. Science 1997;275:550-553. [PubMed: 8999803]

13. Genomic DNA was extracted from the fungal tissue using the Wizard® Genomic DNA Purification Kit (Promega Corporation, Madison, WI) and used in a Polymerase Chain Reaction with primers LR0R (5'-ACCCGCTGAACTTAAGC-3') and LR5 (5'-TCCTGAGGGAAACTTCG-3') to 
amplify a 900 base pair fragment of the large subunit ribosomal DNA. The PCR product was cloned and sequenced, and the consensus sequence used in a BLAST search to identify closely related fungi.

14. Culture conditions tested included stationary and shaken cultures in potato dextrose broth, and rich/ poor culture conditions (a carbon-rich seed followed by carbon-poor production medium), as well as culturing on solid media including cracked corn, rice, and Fiber One cereal. The optimized culture conditions were as follows. Agar plugs of FA39 were used to inoculate seed cultures in potato dextrose broth at $25^{\circ} \mathrm{C}$. The three-day old seed cultures were then used to inoculate flasks containing Fiber One cereal that had been wetted with $0.1 \%$ yeast extract. The fungus was allowed to grow for seven days at $25{ }^{\circ} \mathrm{C}$ prior to extraction. A control extract of Fiber One cereal was inactive.

15. Numbering used is the same as for the spirostaphylotrichins: Sandmeier P, Tamm C. Helv. Chim. Acta 1989;72:774-783.

16. UV $\lambda_{\max }\left(\mathrm{CH}_{3} \mathrm{CN}\right) 262 \mathrm{~nm}$; IR (NaCl, thin film) $v_{\max }: 3421,2956,2931,2860,1706,1633,1445$, $1087,1064 \mathrm{~cm}^{-1},{ }^{13} \mathrm{C}$ NMR (DMSO- $\left.d_{6}, \delta\right): 166.5$ (C-1), $155.2(\mathrm{C}-4), 137.0(\mathrm{C}-3), 104.7$ (C-5), 90.8 (C-14), 86.2 (C-8), 70.8 (C-7), 64.1 (C-6), 63.7 (C-16), 30.8 (C-11), 27.5 (C-9), 25.9 (C-10), 21.9 (C-12), 20.5 (C-15), 13.8 (C-13); ${ }^{1} \mathrm{H}$ NMR (500 MHz, DMSO- $\left.d_{6}, \delta\right): 5.44$ (d, $\left.J=5.5 \mathrm{~Hz}, 1 \mathrm{H}, \mathrm{OH}-6\right)$, 4.97 (d, $J=1.8 \mathrm{~Hz}, 1 \mathrm{H}, \mathrm{H}-14 \mathrm{a}), 4.96$ (d, $J=1.8 \mathrm{~Hz}, 1 \mathrm{H}, \mathrm{H}-14 \mathrm{~b}), 4.92$ (s, 1H, OH-7), 4.07 (d, $J=$ $11.5 \mathrm{~Hz}, 1 \mathrm{H}, \mathrm{H}-8), 3.86$ (d, J = 5.5 Hz, 1H, H-6), 3.79 (s, 3H, H-16), 1.82 (m, 1H, H-9a), 1.51 (m, 1H, H-9b), 1.44 (m, 2H, H-10), 1.28 (m, 2H, H-12), 1.27 (m, 2H, H-11), 1.18 (s, 3H, H-15), 0.85 (t, $J=6.7,3 \mathrm{H}, \mathrm{H}-13$ ). Not all signals could be accurately integrated due to overlap.

17. Dry 4 was stirred in dichloromethane on ice with 4.5 equivalents of $N, N$-diisopropylethylamine, 4 equivalents of $p$-bromobenzoyl chloride, and a catalytic amount of dimethylaminopyridine. The reaction was allowed to slowly warm to room temperature and was stirred until complete disappearance of $\mathbf{4}$, as observed by LCMS.

18. UV $\lambda_{\max }\left(\mathrm{CH}_{3} \mathrm{CN}\right) 262 \mathrm{~nm}$; IR (NaCl, thin film) $\psi_{\max }: 3387,1955,2932,2859,1701,1637,1444$, $1058,1012 \mathrm{~cm}^{-1},{ }^{13} \mathrm{C}$ NMR (DMSO- $\left.d_{6}, \delta\right): 165.3$ (C-1), $156.8(\mathrm{C}-4), 136.0(\mathrm{C}-3), 105.0(\mathrm{C}-5), 91.4$ (C-14), 80.3 (C-8), 69.4 (C-7), 63.6 (C-6), 63.4 (C-16), 30.8 (C-11), 26.6 (C-9), 25.1 (C-10), 21.6 (C-12), 17.9 (C-15), 13.7 (C-13); ${ }^{1} \mathrm{H}$ NMR (500 MHz, DMSO- $\left.d_{6}, \delta\right): 5.49$ (d, $\left.J=5.9,1 \mathrm{H}, \mathrm{OH}-6\right)$, 5.03 (d, $J=2.0,1 \mathrm{H}, \mathrm{H}-14 \mathrm{a}), 5.02$ (d, $J=2.0,1 \mathrm{H}, \mathrm{H}-14 \mathrm{~b}), 4.59$ (s, 1H, OH-7), 3.98 (dd, $J=10.6 \mathrm{~Hz}$, $J=1.8 \mathrm{~Hz}, 1 \mathrm{H}, \mathrm{H}-8), 3.78$ (s, 3H, H-16), 3.75 (d, $J=5.9 \mathrm{~Hz}, 1 \mathrm{H}, \mathrm{H}-6), 1.86$ (m, 1H, H-9a), 1.63 (m, 2H, H-10), 1.54 (m, 1H, H-9b), 1.33 (m, 2H, H-12), 1.32 (m, 2H, H-11), 0.90 (m, 3H, H-13), 0.88 (s, 3H, H-15). Not all signals could be accurately integrated due to overlap.

19. Abraham W-R, Meyer H, Abate D. Tetrahedron 1995;51:4947-4952.

20. Peter, H.; Auden, JAL. 1986. (Ciba-Geigy A.-G., Switz.). Patent DE 3522578

21. a Sugawara F, Takahashi N, Strobel GA, Strobel SA, Lu HSM, Clardy J. J. Am. Chem. Soc 1988;110:4086-4087. b Hallock YF, Lu HSM, Clardy J, Strobel GA, Sugawara F, Samsoedin R, Yoshida S. J. Nat. Prod 1993;56:747-754.

22. For reviews see: a Gunatilaka AA. J. Nat. Prod 2006;69:509-526. [PubMed: 16562864] b Schulz B, Boyle C, Draeger S, Roemmert A-K, Krohn K. Mycol. Res 2002;106:996-1004. c Tan RX, Zou WX. Nat. Prod. Rep 2001;18:448-459. [PubMed: 11548053] 


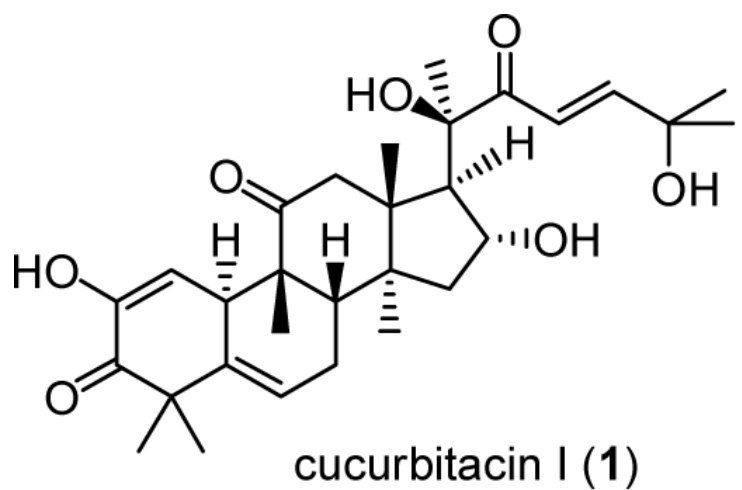<smiles>Oc1ccc(/C=C/c2cc(O)cc(O)c2)cc1</smiles><smiles>CN1CC[C@H](c2c(O)cc(O)c3c(=O)cc(-c4ccccc4Cl)oc23)[C@H](O)C1</smiles>

resveratrol (2)

Figure 1.

Selected inhibitors of STAT3 signaling. 


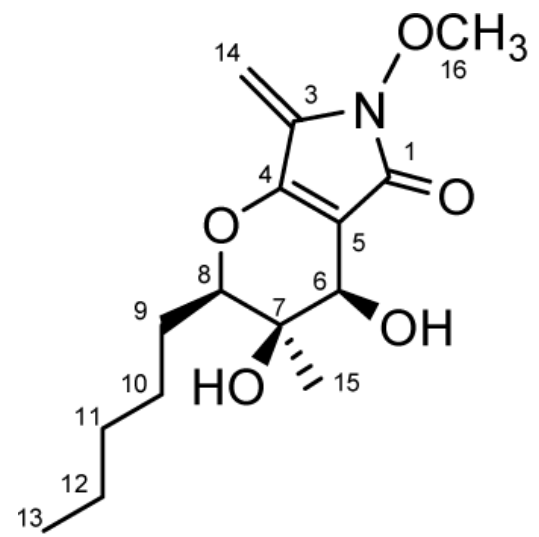

phaeosphaeride A (4)

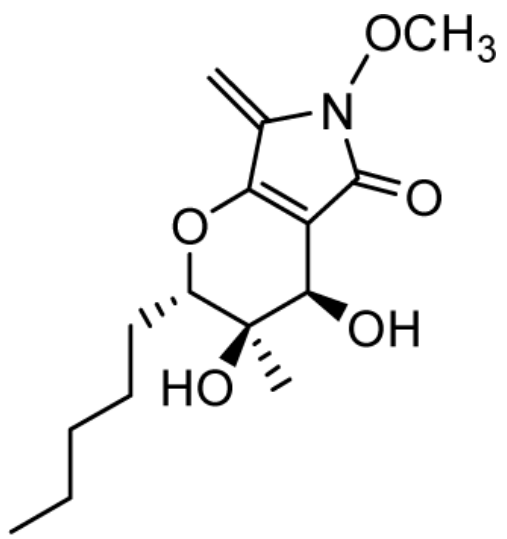

phaeosphaeride B (5)

Figure 2.

Structures (including relative stereochemistry) of the phaeosphaerides. 15 


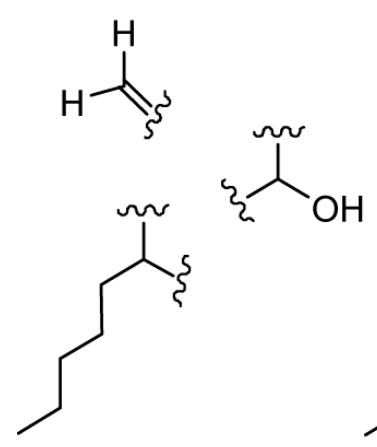

a

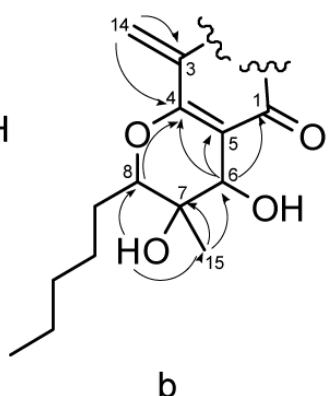

b

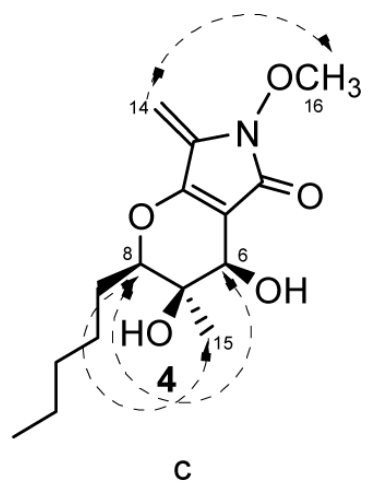

C

$\frown \mathrm{HMBC}$

Figure 3.

(a) Spin systems observed in the dqfCOSY spectrum of phaeosphaeride A (4). (b) Important HMBC correlations for 4. (c) Important NOEs for 4. 

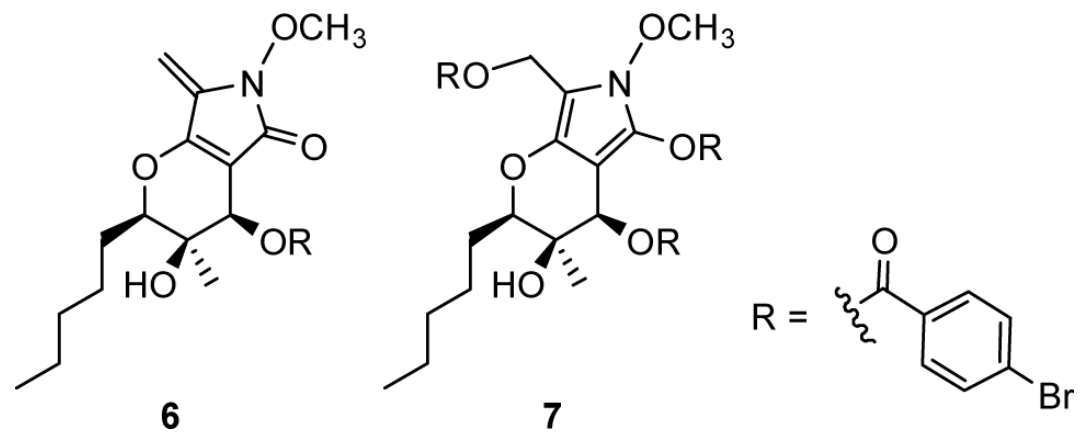

Figure 4.

$p$-Bromobenzoyl derivatives of phaeosphaeride A. 

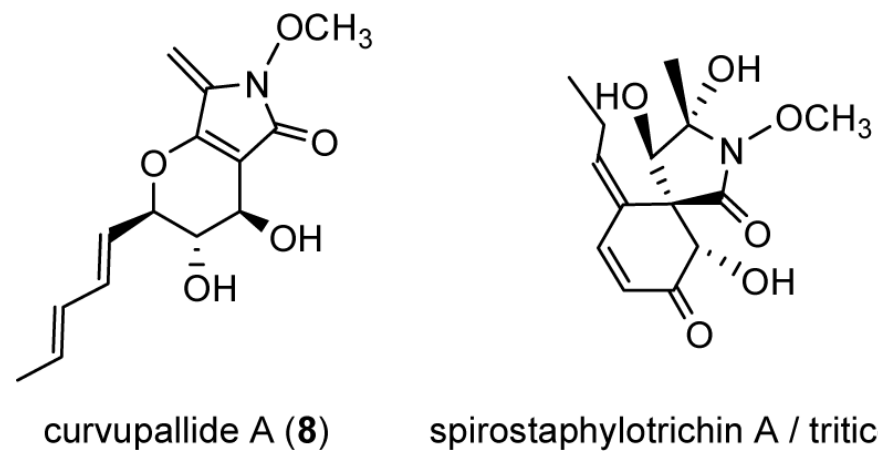

\section{curvupallide A (8) $\quad$ spirostaphylotrichin A / triticone C (9)}

Figure 5.

Fungal metabolites related to the phaeosphaerides. 


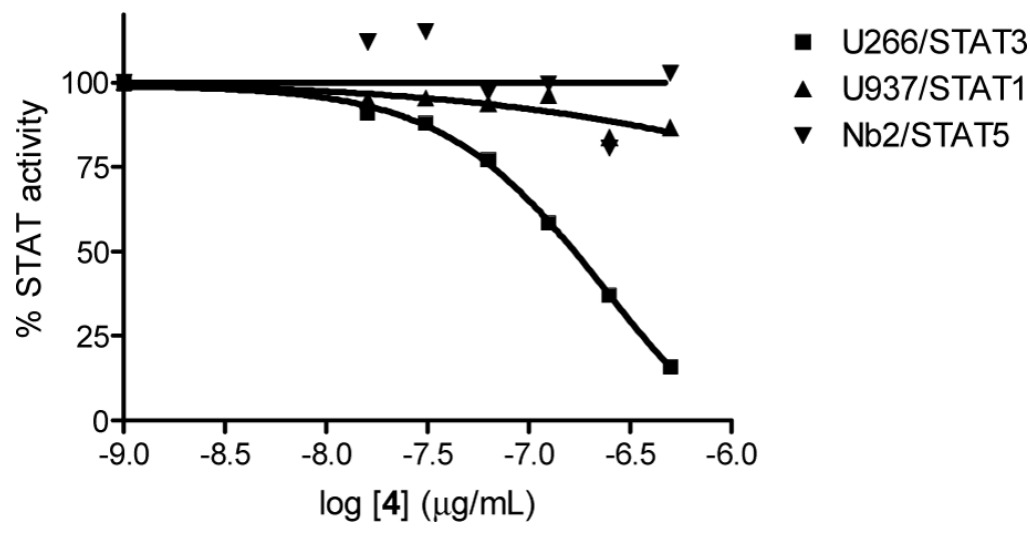

Figure 6.

Phaeosphaeride A (4) selectively inhibits STAT3. Data shown is from ELISA using wholecell lysates of the indicated cancer cell lines. 